\title{
Effect of Overweight and Obesity on Postprandial Lipemia among the Subjects with Type 2 Diabetes
}

\section{Amrane Nadia *\# and Khaled Meghit Boumediene*}

Biology Department, Science faculty of Djillali Liabes University, Sidi Bel Abbes, Algeria "Equal Contribution

\begin{abstract}
Introduction: The prevalence of type 2 diabetes mellitus (DM) and obesity is actually mountingspeedily in Westernized and developing countries. Type 2 diabetes (T2D) is a complex pathology with several risk factors. It is recently known through several studies that postprandial hyperlipemia is a significant and independent risk factor for cardiovascular disease. In fact, numerous alterations in plasma lipid and lipoprotein concentrations are found in obese patients.

Method: The study, which concerned 51 patients with type 2 diabetes, took place in Diabetic Center (Ex. Gambetta) and in the division of Diabetes and Endocrinology at University Hospital (Hassani Abdelkader, Sidi-Bel-Abbès). The aim was to evaluate the relationship between the postprandial lipemia response and overweight and obesity in the type 2 diabetes. The weight, height, waist and hip circumferences, Body Mass Index (BMI) and Waist to Hip Ratio (WHR) were measured. Blood samples were analyzed for total cholesterol, glucose, triglycerides, HDL-cholesterol and LDL-c $2 \mathrm{~h}$ after meal, fasting glucose.

Result: The obtained result determined a correlation between postprandial triglycerides concentration and the BMI especially in overweight and obese women with $r^{2}=0.09$ and correlation $r^{2}=0.01$ for men. PPHDL-c was highly elevated among women than men with a significant differences $(60.44 \pm 24.17 \mathrm{mg} / \mathrm{dL}$ vs. $43.30 \pm 18.27 \mathrm{mg} / \mathrm{dL} ; \mathrm{p}=0.016)$.PPTG among women than men with significant differences $(168.33 \pm 71.37 \mathrm{mg} / \mathrm{dL}$ vs. $121.87 \pm 60.84 \mathrm{mg} / \mathrm{dL} ; \mathrm{p}=003)$. It has been noticed that the PPHDL-c was inversely linked to fasting glucose levels $\left(r^{2}=0.07\right)$ and to the $B M I$ values $(r=0.12 ; p=0.34)$ among women.
\end{abstract}

Conclusion: The management and loss of weight still indispensible for type 2 diabetic subjects especially overweight and obese women one to avoid postprandial hypertriglyceridemia and its complications mainly coronary heart disease.

Keywords: Overweight; Obesity; Postprandial lipemia; Type2 diabetes

\section{Background}

Overall, the prevalence of type 2 diabetes mellitus (DM) is actually mounting speedily in Westernized and developing countries, making it one of the most frequent diseases in the world. The number of adults with DM worldwide is predictable to increase from 135 million in 1995 to 300 million in 2025 [1].

Type 2 diabetes (T2D) is a complex pathology with several risk factors, including an intensifying number of known susceptibility variants. In this term, some of the intermediate characteristic of T2D such as obesity and raised fasting plasma glucose, likewise has complex determinants and indeed both BMI and fasting plasma glucose also tend to augment with age [2]. In fact, numerous alterations in plasma lipid and lipoprotein concentrations are found in obese patients. Tomkin (2008) underlined that Diabetes is associated with major abnormalities in fatty acid metabolism reflected in an abnormal lipoprotein cascade from the large chylomicron through to the small HDL particle.

In this respect, alterations in plasma lipoprotein-lipid concentrations are recognized to enlarge the risk of coronary artery disease $(\mathrm{CAD})$ in both men and women [3]

In fact, these observations raise the question of the impact of postprandial dyslipidemia on overweight and obesity among the type 2 diabetes in one hand and aggravation of subjects' state in the other hand.

In other words, the physiological and biochemical response to a dietary perturbation is most commonly complicated. The postprandial response reveals multiple aspects of metabolic health that would not be noticeable from studying the fasting (homeostatic) parameters [4].

Although, fasting lipid and lipoprotein levels reflect steady state lipid metabolism even healthy subjects is in a state of post-prandial hypertriglyceridemia most of the time due to meal frequency [3]. Cholesterol is indispensable for the maintenance of cellular membrane, production of steroid hormones and bile acids and triglyceride (TG) to provide energy during metabolic needs or storage thereafter in the muscles and adipocytes [5]. Furthermore, it has been reported that obesity [6] and body fat distribution all affect dietary fat clearance [7].

However, historically obesity has been considered as a sign of a prosperous and wealthy society, today obesity has become a major health problem in both developed and developing countries. The filling of tissue cells fat by lipid-based obesity is typically a postprandial phenomenon [8].

Accumulation of triglycerides in fasting plasma is extremely involved, and in fact, over-production of hepatic very low density lipoprotein (VLDL) and/or reduced clearance of these particles from the plasma have been shown in obese subjects [9]. Recently, numerous studies have shown disturbances in postprandial lipid and lipoprotein responses in diabetic subjects as reviewed and the role of obesity on postprandial lipid metabolism has been studied in some occasions.

Now it is evident that high carbohydrate diets increase fasting plasma triglycerol concentrations [10-11] and decrease HDL cholesterol concentrations [11].

*Corresponding author: Amrane Nadia, Biology Department, Science faculty of Djillali Liabes University, Sidi Bel Abbes, Algeria, E-mail: nadia.amrane@rocketmail.com

Received November 30, 2011; Accepted February 23, 2012; Published February 27,2012

Citation: Nadia A, Boumediene KM (2012) Effect of Overweight and Obesity on Postprandial Lipemia among the Subjects with Type 2 Diabetes. J Diabetes Metab 3:178. doi:10.4172/2155-6156.1000178

Copyright: (C) 2012 Nadia A, et al. This is an open-access article distributed unde the terms of the Creative Commons Attribution License, which permits unrestricted use, distribution, and reproduction in any medium, provided the original author and source are credited. 
Carbohydrates increase levels of triglycerol, total cholesterol, and low density lipoprotein (LDL) and decreases HDL cholesterol. It is well known that a high carbohydrate diet, particularly one that is high in extrinsic sugars, leads to an increase in fasting plasma TAG concentrations [12]. The common argument against the consumption of high-fat diet is that it causes obesity [11].

The postprandial state is characterized by a fast rise in triglyceriderich lipoproteins (TRLs) derived from the intestine as chylomicrons, containing apolipoprotein (apo) B-48, and from the liver as very low density lipoprotein (VLDL), containing apo B-100 [13]. Fasting plasma TAG concentrations are typically higher in obesity, and this is associated with enhanced hepatic secretion of VLDL [14]. The key elements of dyslipidemia also constitute excessive postprandial lipemia and remnant accumulation, small dense LDL and small dense HDL particles [15].

The aim of this study was to evaluate the relationship between the postprandial lipemia response and overweight and obesity in the type 2 diabetes.

\section{Material}

\section{Patients and study design}

This study was realized during five months; from April until August 2009. 51 diabetic patients ( 30 women, 21 men), participated in this work, living in Sidi Bel Abbès city (Northwestern region of Algeria), and followed in the diabetes Centre (Ex Gambetta) and the Hassani Abdelkader University Hospital.

Obesity has been defined by body mass index $\left(\mathrm{kg} / \mathrm{m}^{2}\right)$ and waist circumference. According to the current classification of the World Health Organization (WHO), body mass index (BMI) greater than 25 is considered overweight, adult who has a BMI of 30 or higher is considered obese. Obesity is further classified into Class I (BMI > 30), Class II $(\mathrm{BMI}>35)$ and Class III $(\mathrm{BMI}>40)$ obesity. In addition to $\mathrm{BMI}$, increased risk of obesity associated metabolic disorders is found in men with waist circumferences greater than or equal to $102 \mathrm{~cm}$ and in women with $88 \mathrm{~cm}$. The extra calories taken in are stored as fat within the body [16].

These subjects took as oral medications, metformin (10) or glimepiride (7) in single or in association (17) or insulin (14). Dyslipidemic (49\%) treated with Statins (83.33\%) and Fibrates (16.67\%), and non dyslipidemic patients (51\%). 25 individuals had high blood pressure $(127 \pm 10.3 \mathrm{mmHg})$.

The diabetes duration average was $9 \pm 7.5$ years. Individuals with type1 diabetes and pregnant women were eliminated from the study.

At first, we explained to all patients the aim of the study and we also instructed them. Then patients were interviewed face to face and received a questionnaire regarding the social situation, medical history, life style (habitual physical activity, former smoking) and control of lipemia. Furthermore, we elaborated a medical card for each diabetic patient in which we recorded the anthropometric and clinical parameters, the health state and the treatment.

We measured weight, height, waist and hip circumferences, Body Mass Index (BMI) and Waist to Hip Ratio (WHR). We used an electronic balance (SECA ${ }^{\circledR}$ - Germany; SECA 731Sauna: Capacity: 150 $\mathrm{Kg}$ /Graduations: $1.000 \mathrm{~g}$ ).

Blood samples were analyzed, in fasting state and 2 hours postprandially after lunch, for total cholesterol, triglycerides, HDL- cholesterol, LDL-cholesterol. In the culinary habit of the Algerian, this meal is the richest and brings the most important amount calories, this one present a high risk for health.

The serum glucose concentration was measured in fasting period. We had chosen at first to study this mechanism at the early stage $2 \mathrm{~h}$ after eating, to recognize the postprandial lipemia processes in one hand and because only a few studies whose underlined this period in the other hand. We indicate that in Algeria, in medical practice, the measurement of PPL $2 \mathrm{~h}$ after lunch was a big challenge. Serum concentration of TG, HDL-C, LDL-C, total cholesterol was determined by the enzymatic colorimetric method as was described $[17,18]$. The serum low density was calculated using the Friedewald formula [19].

\section{Statistical analysis}

The statistical analysis was performed using the statistical analysis program Statview (5.0 SAS Institute). The student's $t$-test was used to compare both states; fasting and postprandial lipemia. The test is considered significant for values of $p<0.05$. The BMI was correlated with PPL and fasting level by using the simple regression. The associations were expressed as standardized regression coefficients (95\% confidence interval) by dividing the dependent and independent variables from the entire study population.

\section{Results}

The Diabetic patients were aged of $61.52 \pm 9.2$ years (Men) and $57.2 \pm 12.11$ (Women), 12 patients were obese: $\mathrm{BMI}>30 \mathrm{~kg} / \mathrm{m}^{2}$ and 23 patients were overweight (Figure 1). Subjects were either sedentary $54.9 \%$ or moderately active $(45 \%)$.

The body weight was higher among diabetic women $(71.93 \pm 10 \mathrm{Kg}$ vs. $69.28 \pm 10.17 \mathrm{Kg}$ ); the body weight is markedly higher particularly among women than ideal body weight values $(71.93 \pm 10 \mathrm{Kg}$ vs. $55.63 \pm 4.3$ $\mathrm{Kg} ; \mathrm{p}<0.0001$ ). Furthermore, the average waist/hip ratio (WHR) for women was $0.93 \pm 0.50$ which determine a central obesity. However, the WHR was acceptable $0.95 \pm 0.90$ for men. It has been noted that the BMI of both men $\left(26.02 \pm 4.08 \mathrm{~m} / \mathrm{Kg}^{2}\right)$ and women $\left(28.6 \pm 5.43 \mathrm{~m} / \mathrm{Kg}^{2}\right)$ reveal in general the presence of overweight.

Concerning the biological parameter (Table 1), there was no significant difference among men and women for fasting glucose values $(2.06 \pm 1 \mathrm{mg} / \mathrm{dL}$ vs. $2.06 \pm 0.9 \mathrm{mg} / \mathrm{dL} ; \mathrm{p}<0.97)$.

The average of postprandial cholesterolemia level (PPTC) was $188.09 \pm 50.4 \mathrm{mg} / \mathrm{dL}$ for men and $214.77 \pm 56 \mathrm{mg} / \mathrm{dL}$ for women. We didn't notice a significant difference between the two sexes $(p=0.34)$. It has been showed that PPHDL-c was highly elevated among women

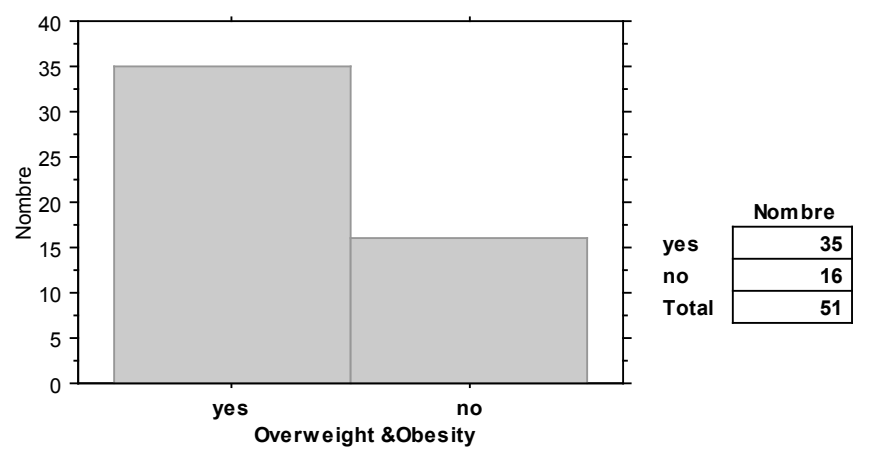

Figure 1: Frequency of overweight and obesity among the sample of this study. 


\begin{tabular}{|l|c|c|c|}
\hline Parameter & Men $\mathbf{( n = 2 1 )}$ & Women $\mathbf{( n = 3 0 )}$ & P values \\
\hline Age (year) & $61.52 \pm 9.2$ & $57.2 \pm 12.11$ & 0.11 \\
\hline Diabete duration (year) & $10.15 \pm 8.08$ & $8.35 \pm 7.49$ & 0.55 \\
\hline Size (cm) & $173.67 \pm 26.53$ & $160.27 \pm 6.46$ & 0.002 \\
\hline Weight (Kg) & $69.28 \pm 10.17$ & $71.93 \pm 10$ & 0.043 \\
\hline Ideal body weight & $63.90 \pm 7.6$ & $55.63 \pm 4.3$ & 0.0005 \\
\hline WC (cm) & $173.67 \pm 26.53$ & $160.27 \pm 6.46$ & 0.025 \\
\hline Hips (cm) & $101 \pm 17$ & $110 \pm 13$ & 0.40 \\
\hline WHR (cm) & $0.93 \pm 0.5$ & $0.95 \pm 0.90$ & 0.489 \\
\hline BMI(Kg/m $\mathbf{2})$ & $26.02 \pm 4.08$ & $28.6 \pm 5.43$ & 0.57 \\
\hline PPTC (mg/dL) & $188.09 \pm 50.4$ & $214.77 \pm 56$ & 0.34 \\
\hline PPHDL-c(mg/dL) & $43.30 \pm 18.27$ & $60.44 \pm 24.17$ & 0.016 \\
\hline PPLDL-c(mg/dL) & $107.43 \pm 46$ & $125.97 \pm 48$ & 0.47 \\
\hline PPTG(mg/dL) & $121.87 \pm 60.84$ & $168.33 \pm 71.37$ & 0.036 \\
\hline FG (mg/dL) & $2.06 \pm 1$ & $2.06 \pm 0.9$ & 0.97 \\
\hline
\end{tabular}

Data are presented as mean values (SD) or percentages. BMI: Body Mass Index; WC: Waist Circumference; WHR: Waist-Hip Ratio; FG: FastingG; FCT: Fasting Total Cholesterol; FTG: Fasting Triglycerides; PPCT: Postprandial Total Cholesterol; PPTG: Postprandial Triglycerides; PPHDL: Postprandial HDL; PPLDL: Postprandial LDL

Table 1: Anthropometric and biological parameters.

than man with a significant differences $(60.44 \pm 24.17 \mathrm{mg} / \mathrm{dL}$ vs. $43.30 \pm 18.27 \mathrm{mg} / \mathrm{dL} ; \mathrm{p}=0.016)$. The obtained results determined a rise of postprandial triglyceridemia (PPTG) among women than men with significant differences $(168.33 \pm 71.37 \mathrm{mg} / \mathrm{dL}$ vs. $121.87 \pm 60.84 \mathrm{mg} / \mathrm{dL}$; $\mathrm{p}=003)$.

As shown in the figure 2, the PPTG levels are linked to the BMI values, for women $\left(r^{2}=0.09\right)$ and with a low correlation for men $\left(r^{2}=\right.$ $0.01)$ according to the regression graph.

An inversely proportional relation was noticed between the postprandial high lipoprotein density (PPHDL-c) and BMI particularly among women diabetics ( $\mathrm{p}=0.34$ ), no significant differences was noted between these two parameters.

As shown in the figure 3, in this study we noticed that diabetic women particularly, obese and overweight had the higher postprandial triglyceridemia and cholesterolemia with $(175 \mathrm{mg} / \mathrm{dL})$ level for PPTG and $(162 \mathrm{mg} / \mathrm{dL})$ for LDL-c.

It has been found (Figure 4) that the PPHDL-c was inversely linked to fasting glucose levels $\left(\mathrm{r}^{2}=0.07\right)$.

\section{Discussion}

It is recently known through several studies that postprandial hyperlipemia is a significant and independent risk factor for cardiovascular disease. In this study we didn't found a correlation between age and PPL in both sexes otherwise [9], have reported that the postprandial lipemia are affected by age. In fact, numerous alterations in plasma lipid and lipoprotein concentrations are found in obese patients. In this respect, prevalence and incidence of overweight and obesity in type 2 diabetes particularly among women raise the question about the effect of this phenomenon on postprandial lipemia defined lately as Zilversmit [20] reported to be implicated in the atherosclerosis. Hypertriglycedimia, low HDL cholesterol and an increased fraction of small dense LDL particles characterize diabetic dyslipidemia, while LDL and total cholesterol are not generally increased in diabetic patients expect for slight increase of LDL cholesterol in women. In addition small LDL is associated with the cluster of risk factors that characterize the insulin resistance syndrome. Moreover, during this investigation we noticed that the Statins are currently the most

prescribe in these divisions. In this respect, Rizzo et al. 2007 [21] mentioned that Hypolipidemic treatment is able to alter LDL subclass distribution and statins are the most widely used lipid-lowering agents. Statins are the main drugs of choice, it potentially lower all subclasses of LDL-c (Large, medium, small particles)

The majority of studies on the description of plasma lipoprotein levels in overweight and obesity have been done in the fasting state, without postprandial lipoproteins which generally being neglected. Indeed, Lewis et al. [6] reported a greater 24-h postprandial response (area under the incremental curve) for plasma TG in obese subjects (BMI $\left.\sim 44 \mathrm{~kg} / \mathrm{m}^{2}\right)$.

We underline that for the reason that obesity was defined only on the basis of BMI, the relationship between visceral adipose tissues accumulation and postprandial lipemia was not investigated.

In this term, the diabetes disease seems to be a foremost a factor causative of the abnormal PPTG response among type 2 diabetic patients as other contributors of alteration of postprandial lipids responses such as sex, body mass index and measures of central obesity which have been carefully controlled in this study.

Several authors newly reported an increase of postprandial triglyceridemia response with visceral obesity compared with others with lower visceral adiposity $[9,10]$. Positive correlations between BMI or intra-abdominal fat and postprandial triglyceridemia have already been reported in some studies [10,22,23].These results accord to our findings.

Overweight and obesity seems to be a influent element on PPL in type 2 DM as high PPTG reflect a good correlation with body mass index (BMI) .Unless, it would appear that the magnitude of PPTG response in type 2 diabetic subjects is mostly determined by an interaction of obesity and the underlying diabetic state as reported by Madhu SV et al. [24]. In fact, Rizzo et al. 2007 [21] suggest that the quality rather than the quantity of lipemia exerts a noteworthy influence on the cardiovascular risks.

Indeed, this observation supports the notion that TG from

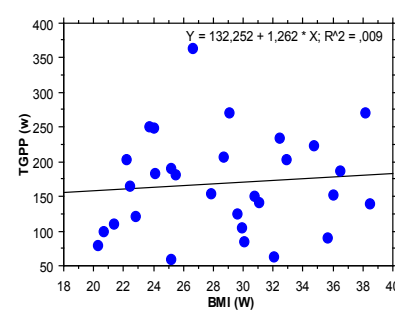

(A)

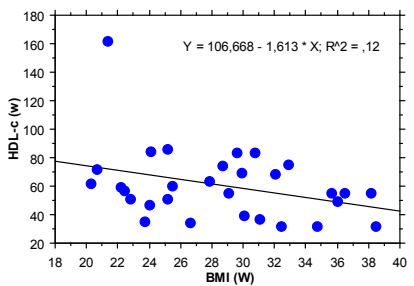

(C)

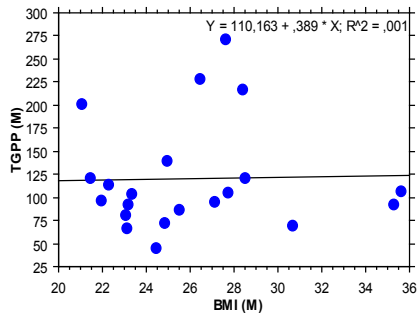

(B)

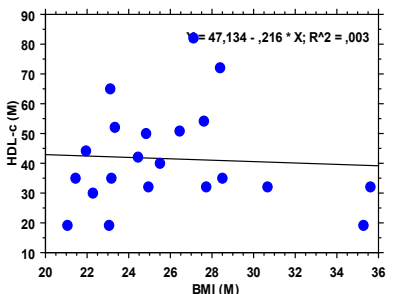

(D)
PPTG (M): Postprandial Triglyceridemia among Men; PPTG (w): Postprandial Triglyceridemia among Women

Figure 2: Relation between postprandial lipemia and BMI among men and women. 


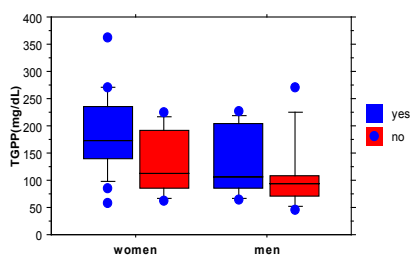

(A)

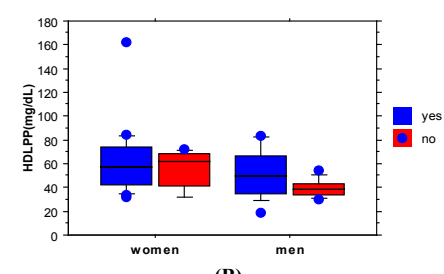

(B)

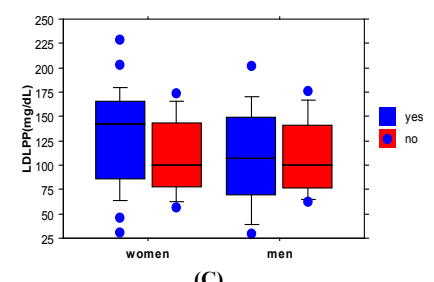

(C)

A: Effect of overweight and obesity on TGPP among women and men; B Effect of overweight and obesity on HDL-C among men and women; C: Effect of overweight and obesity on LDL-C among men and women.

Figure 3: Contribution of overweight and obesity in the increase of postprandial lipemia $(n=51)$.

Yes: present overweight or obesity; no: normal weight.

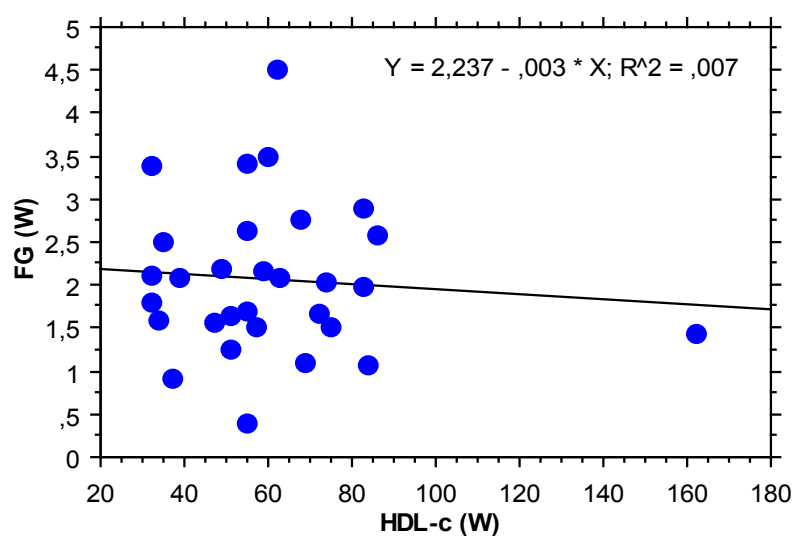

Figure 4: Contribution of PPHDL-c in the decrease of fasting glycemia.

endogenous TRLs, seemingly VLDL particles, account for most of the increase in TG levels observed late during the postprandial period among overweight and obese individuals in one hand and suggests that reduced PH-LPL activity may be implicated in the altered postprandial TRL metabolism among viscerally obese subjects in the other hand [6]. In this line, the elevation of VLDL among overweight and obese individuals may explain the inversely proportional relation between PPHDL-c and BMI.

In Postprandial period, insulin resistance has the key role in both hepatically- and intestinally-derived TRL. In this respect, the android type of obesity seems directly implicated in postprandial disturbances, whereas the gynoid type is not or only marginally [10].

Higher activity of lipoprotein lipase known among women may explain HDL-c accumulation in the postprandial state, as observed in this study. It has been reported that when the fat intake is increased, the capacity to hydrolyze triglycerides may become a rate limiting factor among men resulting in high PPTG. This may explain the observed increased in HDL-C in women but not men [25]. It should be mention that the average age of diabetic women in this study is $57.2 \pm 12.11$ which determined that they are menopausal, this explain the higher level of triglycerides.

Few studies have meticulously examined the impact of metabolism of carbohydrate on risk factors for cardiovascular disease including postprandial lipemia [23]. Although carbohydrate restriction could favorably impact certain aspects of lipid metabolism such as decreasing hepatic production of triacylglycerols Volek SJ et al. [23] reported that The very low-carbohydrate diet did not lower LDL-C, but it prevented the decline in HDL-C also resulting in no change in the total cholesterol/HDL-C ratio and indicated that postprandial triacylglycerols are higher in obesity, especially abdominal obesity [22]. High blood glucose levels are the result of damaged $\beta$ cell function. In addition, high blood glucose levels also damage $\beta$ cell function. The first lipid abnormality to become apparent in pre-diabetes seems to be the raised fatty acids. This interrelationship between blood glucose and lipids in tissue damage is seen, not only in the cell, but also in the arterial wall and it is the complications of diabetes, and particularly the vascular complications of diabetes [26].

We found inversely proportional relation between PPHDL-c and Fasting glucose values. Although there is no doubt about the association between blood glucose and atherosclerosis, only a few studies have been able to show an improvement in cardiovascular outcome by reduction in blood glucose. It has been suggested that diabetes should not be called mellitus butrather lipidus [26]. Tomkin (2008) mentioned that achieving normal glycemia will overturn the abnormalities in fatty acid metabolism, but this is difficult, particularly as the disease progresses [26].

Unfortunately, few studies have conversely examined the effect of moderate weight loss on postprandial lipemia among women and men.

\section{Conclusion}

Type 2 diabetes is a severe pathology with serious complication in the long term specially the coronary heart disease affected by postprandial dyslipidemia and obesity effect particularly among women diabetic. In this line, the management and loss of weight still indispensible to avoid postprandial hypertriglyceridemia mainly. It has been showed in this study relation between PPL and BMI and that PPHDL-c are linked to the BMI values and fasting glucose too which is also interacted with obesity phenomenon.

\section{Acknowledgments}

The authors are grateful for the help of physicians working in Diabetes Centre (Ex Gambetta) and the staff of Hassani Abdelkader Hospital University of Sidi-BelAbbès particularly the department of Diabetology \& Endocrinology.

\section{References}

1. King $\mathrm{H}$, Aubert RE, Herman WH (1998) Global burden of diabetes, 1995-2025: prevalence, numerical estimates, and projections. Diabetes Care 21: 14141431.

2. Webster JR, Warrington NM, Beilby JP, Frayling MT, Palmer JL (2010) The longitudinal association of common susceptibility variants for type 2 diabetes and obesity with fasting glucose level and BMI. BMC Medical Genetics 11: 140.

3. Dubois C, Armand M, Azais-Braesco V, Portugal H, Pauli AM, et al. (1994) Effects of moderate amounts of emulsified dietary fat on postprandial lipemia and lipoproteins in normolipidemic adults. Am J Clin Nutr 60: 374-382.

4. van Ommen B, Keijer J, Kleemann R, Elliott R, Drevon C, et al. (2008) The challenges for molecular nutrition research 2: Quantification of the nutritional phenotype. Genes Nutr 3: 51-59.

5. (2002)Third Report of the National Cholesterol Education Programme (NCEP) Expert Pannel on Detection, Evaluation, and Treatment of High Blood 
Citation: Nadia A, Boumediene KM (2012) Effect of Overweight and Obesity on Postprandial Lipemia among the Subjects with Type 2 Diabetes. J Diabetes Metab 3:178. doi:10.4172/2155-6156.1000178

Page 5 of 5

Cholesterol in Adults(Adult treatment Pannel III) final report. Circulation 106: 3143-3421.

6. Lewis GF, O'Meara NM, Soltys PA, Blackman JD, Iverius PH, et al. (1991) Fasting hypertriglyceridemia in non insulin-dependent diabetes mellitus is an important predictor of postprandial lipid and lipoprotein abnormalities. J Clin Endocrinol Metab 72: 934-944.

7. Couillard C, Bergeron N, Prud'homme D, Bergeron J, Tremblay A, et al. (1999) Gender Difference in Postprandial Lipemia : Importance of Visceral Adipose Tissue Accumulation. Arterioscler Thromb Vasc Biol 19: 2448-2455.

8. Ogden CL, Carroll MD, Curtin LR, Mc Dowell MA, Tabak CJ, et al. (2006) Prevalence of overweight and obesity in the United States, 1999-2004. JAMA 295: 1549-1555.

9. Lairon D (2009) Le métabolisme postprandial des lipides: une autre vision sur les relations alimentation métabolisme- santé. CERIN 112: 1-6.

10. Mekki N, Christofilis MA, Charbonnier M, Atlan-Gepner C, Defoort C, et al. (1999) Influenceof obesity and body fat distribution on postprandial lipemia and triglyceride-rich lipoproteins in adult women. J Clin Endocrinol Metab 84: 184191.

11. Coulston AM, Liu GC, Reaven GM (1983) Plasma glucose, insulin and lipid responses to high-carbohydrate low-fat diets in normal humans. Metabolism 32: 52-56.

12. Dashti MH, Mathew TC (2009) Prevention of Obesity Using Low Carbohydrate Ketogenic Diet. Kuwait Medical Journal 41: 3 -12.

13. Chong MF, Fielding BA, Frayn KN (2007) metabolic interaction of dietary sugars andplasma lipids with a focus on mechanisms and de novo lipogenesis. Proc Nutr Soc 66: 52-59.

14. Enkhmaa B , Ozturk Z, Anuurad E , Berglund L (2010) Postprandial Lipoproteins and Cardiovascular Disease Risk in Diabetes Mellitus.Curr Diab Rep 10: 61-69.

15. Cummings MH, Watts GF, Pal C, Umpleby M, Hennessy TR, et al. (1995) Increased hepatic secretion of very-low-density lipoprotein apolipoprotein B-100 in obesity: a stable isotope study. Clin Sci (Lond) 88: 225-233.

16. Taskinen MR (2010) Abnormalities of triglyceride rich lipoproteins (TRLs) in type 2 diabetes and insulin resistance. Clin Invest Arterioscl 22: 36-38.
17. Allain CC, Poon Ls, Chan CSG, Richmond W, Fu PC (1975) Enzymatic determination of total serum cholesterol. Clin Chem 20: 470-475.

18. Wahelefeld AW (1974) Triglycerides-Determination after enzymatic hydrolysis In: Bergmeyer HU, ed. Methods of enzymatic Analysis. New York: Academic Press 4: 1831-1835.

19. Friedewald WT, Levy RI, Fredrickson DS (1972) Estimation of the concentration of the low-density lipoprotein cholesterol in plasma, without use of the preparative ultracentrifuge. Clin Chem 18: 499-502.

20. Zilversmit DB (1979) Atherogenesis: a postprandial phenomenon. Circulation 60: $473-485$.

21. Rizzo M, Rini GB, Berneis K (2007) The clinical relevance of LDL size and subclasses modulation in patients with Type-2 diabetes. Exp Clin Endocrinol Diabetes 115: 477-482.

22. Couillard C, Bergeron N, Prud'homme D, Bergeron J, Tremblay A, et al. (1998) Postprandial triglyceride response in visceral obesity in men. Diabetes 47: 953960.

23. Volek SJ, Sharman MJ, Go'mez AL, DiPasquale C, Roti M, et al. (2004) Comparison of a Very Low-Carbohydrate and Low-Fat Diet on Fasting Lipids, LDL Subclasses, Insulin Resistance, and Postprandial Lipemic Responses in Overweight Women. J Am Coll Nutr 23: 177-184.

24. Madhu SV, Mittal V, Krishna Ram B, Srivastava DK (2005) Postprandial Lipid Abnormalities in Type 2 Diabetes Mellitus. J Assoc Physicians India 53: 10431046.

25. Kovár J, Poledne R (2000) Sex differences in the response of postprandia lipemia to a change from a low-fat low-cholesterol diet to a high-fat highcholesterol diet. Physiol Res 49: 233-239.

26. Tomkin GH (2008) Targets for intervention in dyslipidemia in diabetes. Diabetes Care 31 : S241-S248.

27. Wideman L, Kaminsky LA, Whaley MH (1996) Postprandial lipemia in obese men with abdominal fat patterning. J Sports Med Phys Fitness 36: 204-210. 